\title{
Trends in Employment for Individuals with Autism Spectrum Disorder: a Review of the Research Literature
}

\author{
June L. Chen • Geraldine Leader • Connie Sung • \\ Michael Leahy
}

Received: 5 November 2014 / Accepted: 11 November 2014 / Published online: 24 December 2014

(C) Springer Science+Business Media New York 2014

\begin{abstract}
Employment is fundamental to the well-being of individuals including those with autism spectrum disorder (ASD). The purposes of this review are to provide an overview of employment-related research in individuals with ASD and increase our understanding of the factors that affect the employment situation of this population. Topics explored are employment outcomes revealed from adult outcome studies and national datasets as well as internal and external
\end{abstract}

The first author is a recipient of the Hegarty Postdoctoral Research Fellowship which is supported by Michigan State University, USA, and the DOCTRID research institute (Daughters of Charity-Technology, Research Into Disability), Dublin, Ireland.

\section{Highlights}

- Employment is fundamental to the well-being of individuals including those with autism spectrum disorder.

- This review will provide an overview of employment-related research.

- Employment outcome studies, social difficulties, comorbidity, education level, family support, employers' attitudes, access to services, and disability incentives will be explored.

- Research evidence for specific employment training programs and strategies to successful employment are examined.

- Supported employment, transition services, assistive technology, and multidisciplinary collaboration are also discussed.

- Implications from both clinical practice and research perspective are provided.

\section{J. L. Chen $\cdot$ C. Sung $\cdot$ M. Leahy}

MSU-DOCTRID (Michigan State University—Daughters of Charity-Technology, Research Into Disability) Research Institute, Hegarty Fellow Program Michigan State University, East Lansing, MI, USA

J. L. Chen · M. Leahy

Department of Counseling, Educational Psychology and Special

Education, Michigan State University, East Lansing, MI, USA

\section{G. Leader $(\bowtie)$}

Irish Centre for Autism and Neurodevelopmental Research, National University of Ireland, Galway, Ireland

e-mail: geraldine.leader@nuigalway.ie challenges that people with ASD may face in finding and maintaining employment. Social difficulties, comorbidity, education level, family support, employers' attitudes, access to services, and disability incentives have been implicated as factors that play an important role in predicting employment. Existing research evidence for specific employment training programs and strategies to successful employment are also introduced in regards to supported employment, transition services, assistive technology, and multidisciplinary collaboration. Finally, implications from both clinical practice and research perspective are provided.

Keywords Employment outcomes · Vocational rehabilitation $\cdot$ Autism spectrum disorder $\cdot$ Transition-aged

\section{Introduction}

The Centers for Disease Control and Prevention (CDC) estimates that 1 in 68 children is identified with an autism spectrum disorder (ASD) in the USA (CDC 2014). There has been a dramatic increase in the prevalence of ASD in the last decade, with CDC reporting 1 in 150 in 2000 (CDC 2000). Shattuck et al. (2012) recently estimated that there are about 50,000 youth with ASD who are turning 18 years old every year in the USA. In 2011, the National Centre for Social Research (NatCen) of the UK reported that 1 in 102 adults in UK was on the spectrum (Brugha et al. 2011). This number has also been identified and accepted by other European countries, such as Germany, Denmark, Finland, Iceland, Sweden, and Ireland (CDC 2014; Vogeley et al. 2013). To date, evidence does not suggest that there will be a decrease in the prevalence of ASD. Therefore, suitable adult services and support, especially employment-related services, are greatly needed for individuals with ASD. 
Being employed involves integrating into a social network, contributing to society, making choices and decisions, being seen as part of a society, and being less reliant upon publically funded programs (Roux et al. 2013). As a necessary component of adult life, employment is one of the most desirable achievements for every individual, including people with ASD, when we enter our adulthood (Bennett and Dukes 2013; Roux et al. 2013; Wilczynski et al. 2013. Successful employment increases an individual's social status and financial independence and maintains a person's physical and psychological health, thereby improving his/her quality of life (Fleming et al. 2013; Gerhardt and Lainer 2011). However, it is sometimes challenging for an individual to gain and maintain a meaningful job, and it is even harder for people with deficits in social skills, such as people with ASD (Hendricks 2010; Müller et al. 2003). Employment involves a complex social dynamic, which continually changes according to different circumstances and requires flexible coping strategies (Shattuck and Roux 2014). The unique features of employment increase the specific challenges for individuals with ASD, who are characterized as experiencing lifelong difficulties in social interactions. Recently, research has investigated employment issues among people with ASD. The main aims of this review paper are to increase our understanding of the current employment situations, challenges to successful employment, and strategies for successful employment of individuals with ASD, and to highlight areas for future research.

\section{Employment Outcomes}

Major priorities of employment-related studies is to investigate employment outcomes of individuals with ASD, and to identify their working status, areas where they are employed, average earnings, and working hours.

\section{Adult Outcome Studies}

Early adult outcome studies have demonstrated a poor employment situation for individuals with ASD. Rutter et al. (1967) followed 63 individuals who received their diagnosis of autism during 1950 to 1958 , and they found that only three individuals had paid jobs when they became adults. Kanner (1973) reported that among 96 individuals who were initially diagnosed with autism, only 11 had jobs by the time they were in their twenties and thirties. Lotter (1974) also reported that among 22 adolescents who were on the spectrum, only 1 found a job after they completed their education. Worldwide adult outcome studies continue to report low employment rates of individuals with ASD. Kobayashi et al. (1992) reported that $20 \%$ were employed in a Japanese sample; Whitehouse et al. (2009) reported an employment rate of $18 \%$ in a UK study. However, Eaves and Ho (2008) illustrated that $56 \%$ of a Canadian sample had worked after entering adulthood.

Underemployment is another common issue among individuals with ASD. Studies illustrate that people on the spectrum are being poorly paid with very limited weekly working hours. Howlin et al. (2004) followed 68 individuals from an average age of 7 to 29 years; they found that only two were working on full salary when they entered adulthood. Eaves and Ho (2008) reported that most of the employed individuals were volunteering or working in part-time jobs, and the average working time was $5 \mathrm{~h}$ a week. Taylor and Seltzer (2011) conducted a longitudinal study which investigated 66 individuals with ASD for 10 years; they found that only $6 \%$ of the participants had competitive jobs, and $12 \%$ were in supported employment, but none of them worked full-time.

Despite the unsatisfactory employment outcomes of individuals with ASD, it has also been reported that people who are employed are generally experiencing better adult outcomes, including better quality of life and cognitive performance, than those who are unemployed (García-Villamisar et al. 2002; Howlin et al. 2004).

The literature has also examined employment outcomes for individuals with high functioning autism and Asperger's syndrome. It was hypothesized that better outcomes should be found among these higher functioning individuals (Howlin 2000). However, the existing studies failed to support this optimistic hypothesis. While a slightly larger number of employment rates were reported, which ranged from 11 to $55 \%$ (Farley et al. 2009; Howlin 2000; Hurlbutt and Chalmers 2004; Larsen and Mouridsen 1997; Szatmari et al. 1989; Venter et al. 1992), the majority of these individuals were underemployed. Studies demonstrated that although these young adults finished their secondary education, and some of them even obtained post-secondary certificates and degrees, they were still being employed in unskilled low-level jobs, working much few hours per week, being poorly paid, and unable to sustain a job for an extended period of time (Howlin 2000; Hurlbutt and Chalmers 2004; Larsen and Mouridsen 1997; Mawhood and Howlin 1999; Müller et al. 2003).

In general, adult outcome studies have provided basic information about employment situations of individuals with ASD, yet their limitations are obvious. First, while most adult outcome studies include employment as part of their outcome variables, limited studies have been conducted to investigate specific employment-related issues. Second, the majority of the studies did not use standardized assessment tools, but rather subjective and narrative descriptions which limit comparisons across studies. Howlin et al. (2000) indicated that the work records of these individuals were usually very unstable. To address this problem, Taylor and Seltzer (2012) developed a vocational index with 11 categories coded on a 9point scale. However, the feasibility of this instrument being 
used in a wide diversity of samples still needs to be examined. Third, for most of the follow-up studies, limited sample size was a crucial issue, with a relatively small number of participants.

\section{National Datasets}

National datasets can also serve as another method of analyzing employment outcomes for individuals with ASD. The current literature mainly reports using data from the National Longitudinal Transition Study-2 (NLTS2) dataset and the Rehabilitation Service Administration (RSA-911) dataset. Both datasets are nationally operated in the USA for collecting service-related information and outcomes of individuals with disabilities.

National Longitudinal Transition Study-2 (NLTS2) With the launch of NLTS2 in the USA in 2001, ASD was for the first time categorized separately in national longitudinal data collection. This database traced individuals' post-school experiences, including academics, employment, and social adjustment (Wagner et al. 2005).

The NLTS2 data continuously reports that young adults with ASD demonstrate the lowest employment rates among people with disabilities. The first wave of data revealed that only $15 \%$ of young adults with ASD were employed during the first year after leaving high school, when compared to the $54 \%$ employment rate of other high school graduates with disabilities (Cameto 2003). The following waves of the data continued to identify the rates of individuals who were employed at least once since high school graduation. While the rate increased steadily for individuals on the spectrum from 15 to $63 \%$, it was always lower than the average rate for all disability groups, which increased from 54 to $91 \%$. The dataset was also used to investigate the number of individuals who were in employment at the point of data collection. Similarly, rates for people on the spectrum (from 37 to $45 \%$ ) were always significantly lower than those for people with other disabilities (from 60 to $72 \%$ ) (Newman et al. 2011; Newman et al. 2010; Sanford et al. 2011).

Other studies using the same dataset also highlighted the vulnerable situation of young adults on the spectrum. Shattuck et al. (2012) found that $55 \%$ of the young adults with ASD had held paid employment during the first 6 years after leaving high school, which was the lowest rate when compared with their peers with learning disability (LD; $94 \%$ ), intellectual disability (ID; $69 \%$ ), and speech/language impairment (SLI; $86 \%$ ). The first 2 years post-high school were the most at risk time for young adults with ASD to be unemployed, as more than $50 \%$ were found to have no participation in any kind of employment or related education. Roux et al. (2013) further reported that besides the lowest employment rate among all disability groups, young adults with ASD also earned a significantly lower wage $(\$ 8.10)$ than their peers with other disabilities (emotional disability, ED, \$11.90; LD, \$11.20; SLI, \$12.00) and one fifth of them worked full-time ( $>35 \mathrm{~h}$ per week) which was about one half the rate of the ID group (40\%) and about one third of the rate of the ED (61\%), LD (73\%), and SLI (63\%) groups. The study also found that young adults with ASD had fewer jobs and less variation in types of jobs than others in comparison groups. Migliore and Zalewska (2012) did discover some encouraging information from the national dataset. They found that although $42 \%$ of the youth on the spectrum earned less than the federal minimum wage, over $85 \%$ of those who had a job reported liking their job very much, or fairly well.

A comparatively comprehensive overview of employment outcomes for young adults with ASD in the USA can be drawn from NLTS2 dataset. Yet, there is a limitation in using this national dataset, because it only traced youth who participated and completed their special education during the data collection years. In other words, no information was collected for those who were not involved in special education services, or who exited the school system before the project was launched. Moreover, when the project was completed in 2009 , no further data has been collected since then.

Rehabilitation Service Administration (RSA-911) Rehabilitation Service Administration (RSA-911) dataset is a nationwide individual-level database that annually collects employment-related information of people with disabilities in the USA who are served through the public rehabilitation program. It provides information about individual's employment status, weekly working hours, and hourly wages, as well as use of state vocational rehabilitation (VR) services, including services of assessment and diagnosis, rehabilitation counseling, college or university training, job placement, onthe-job support, etc. (Dutta et al. 2008; Wittenburg and Maag 2002).

The needs for VR services among adults with ASD rapidly increased after 2000. Cimera and Cowan (2009) illustrated an increase of more than $121 \%$ from 2002 to 2006 . From 2006 to 2010, the number kept increasing by $130 \%$ (Migliore et al. 2014). Recently, Burgess and Cimera (2014) reported that from 2002 to 2011, the number of adults with ASD seeking VR services increased by $792 \%$.

Compelling facts of employment outcomes and related VR service provision have been revealed by examining the RSA911 dataset. Schaller and Yang (2005) indicated that among 1323 service seekers who were on the spectrum, $62 \%$ received either services for competitive employment or supported employment service, and $66 \%$ achieved successful employment after receiving VR services. Similar results were reported by Lawer et al. (2009), that $42 \%$ of service users with ASD obtained employment when they exited the VR system, which is the highest among all the participants in their 
study (other service users included individuals with intellectual disability (39\%), specific learning disability (38\%), and other impairment (35\%)). Migliore et al. (2014) confirmed the findings by longitudinally examining the rehabilitation rates from 2006 to 2010. They found that youth with ASD always had a higher rehabilitation rate (50-58 \%) than their peers with ID (44-52\%) or other disabilities (46-55\%). These results were quite encouraging in assuring an optimal rehabilitation outcome of individuals with ASD, if appropriate rehabilitation services and support are provided. Nevertheless, researchers also stated that these findings were not representative of the whole ASD population. Lawer et al. (2009) indicated that there were still a large number of people on the spectrum who had not received VR services due to different reasons, such as low motivation for seeking services or employment, ineligible for VR services. A lower employment rate would be expected if a more representative group is included in analysis.

The data for working hours and hourly wages provided additional information on individuals' employment states. Burgess and Cimera (2014) reported that the hours worked per week by young adults with ASD were fairly stable, ranging from 22 to $26 \mathrm{~h}$, and their mean weekly wage over the past decade ranged from $\$ 175$ to $\$ 216$. However, these figures were among the lowest in the VR system (average weekly working hours for people in VR system ranged from 29 to $32 \mathrm{~h}$, average weekly earnings ranged from \$271 to \$322). The results highlighted that individuals with ASD were underemployed (Baldwin et al. 2014), and the situation has not been improved across the years (Bennett and Dukes 2013).

As a government administrative dataset, RSA-911 provides ongoing data for examining the employment outcomes and related services for people with ASD. However, there are certain limitations, because the data is only available for individuals who are receiving VR services from public rehabilitation programs. Furthermore, errors and differences in the data collection are inevitable (Chan et al. 2008).

\section{Challenges to Successful Employment}

The literature has examined internal challenges to successful employment for individuals with ASD, which includes social deficits, challenging behaviors, comorbidity, and educational level. External factors, such as employers' characteristics, vocational services, receiving disability-related benefits, and family socioeconomic status, were also investigated.

\section{Internal Challenging Factors}

Social Difficulties Current research suggests that social deficits are a significant barrier to successful employment for people with ASD (Hendricks 2010; Patterson and Rafferty 2001). Chiang et al. (2013) examined 830 cases of secondary school graduates who were on the spectrum; they found that those with poor social skills were significantly less likely to be employed.

Difficulties in social communication were highlighted in the literature. By assessing four employment cases of individuals with ASD, Burt et al. (1991) demonstrated how social deficits contribute to an inability to retain a job, including rudely terminating or interrupting conversations, inability to communicate needs, lack of spontaneous speech, and inappropriate use of trendy language phrases. Hagner and Cooney (2005) investigated 14 supervisors and further indicated that inefficient verbal and nonverbal communications directly impact individuals' job performance. Sperry and Mesibov (2005) interviewed 18 adults with ASD; they found that difficulty with maintaining communication in the workplace usually caused difficulties in interactions with supervisors and co-workers, which might lead the employment to be ended prematurely. Studies showed that while people with high functioning ASD and Asperger's typically do not have difficulties with job tasks, deficits in social interaction are a major obstacle in their employment (Hurlbutt and Chalmers 2004). Müller et al. (2003) reported that the majority of individuals with Asperger's were described as unable to complete their work, because they failed to understand working instructions. Many people with high-functioning ASD experienced employment terminations because of their deficits in social communication, such as having difficulties in reading between the lines, being unable to understand facial expressions and tones of voice, and asking too many questions (Baldwin et al. 2014; Bolman 2008; Hurlbutt and Chalmers 2004; Müller et al. 2003).

Wing (1989) identified social immaturity and social naivety as inappropriate social behaviors which are not acceptable in adulthood. The author indicated that these behaviors were commonly observed in adults with ASD, and they often hampered a person's social activities. Howlin et al.'s (2005) study showed that socially inappropriate behaviors were one of the principal difficulties for people with ASD in the workplace. Poor hygiene and grooming skills, inability to understand others' emotions, and acting inappropriately with individuals of the opposite sex were reported as hindrances for employment among individuals with ASD (Burt et al. 1991; Hendricks 2010; Hurlbutt and Chalmers 2002; Patterson and Rafferty 2001). Hurlbutt and Chalmers (2002, 2004), Müller et al. (2003), and Bolman (2008) all identified cases where an individual's employment was terminated due to inappropriate social behaviors. Adolescents on the spectrum also selfreported that being perceived as "socially awkward" was a significant obstacle in the workplace (Giarelli et al. 2013).

Some researchers have investigated the social difficulties that are presented in an interview situation. The intensive 
challenges during their job interviews caused by social deficits were frequently reported among people with ASD, especially those with Asperger's and high-functioning ASD (Mawhood and Howlin 1999; Smith et al. 2014; Strickland et al. 2013). Müller et al. (2003) indicated that poor interview performances limited job opportunities for people on the spectrum, regardless of their working capability. Giarelli et al. (2013) interviewed young adults with ASD who identified their social impairments during the interview process as the most problematic issue for getting hired for a job. López and Keenan (2014) suggested that vocational practitioners should provide training for individuals with ASD in order to enhance their social skills for overcoming the challenges during the interview process.

Challenging Behaviors Challenging behaviors is another major obstacle for successful employment among individuals with ASD (Chiang et al. 2013; Hendricks 2010; Test et al. 2014; Wehman et al. 2014). ASD phenotypic behaviors, ritualistic activities, and inflexible routines were reported as barriers for an individual with ASD in the daily workplace (Schall 2010; Test et al. 2014). Other relevant behaviors, such as yelling, tantrums, poor attention to task, hyperactivity, uncooperative behaviors, obsessive behaviors, aggression, and property destruction, as well as self-injured behaviors, are extremely problematic and concerning in the workplace (Burt et al. 1991; Capo 2001; Howlin et al. 2005; Kobayashi et al. 1992; Patterson and Rafferty 2001; Shattuck et al. 2007). Studies have demonstrated that people who exhibit more challenging behaviors have less opportunity for employment (Eaves and Ho 2008; Howlin et al. 2005; Keel et al. 1997; Rumsey et al. 1985; Taylor and Seltzer 2011; Wehman et al. 2013). When compared to job-task-related problems, behavior problems were more unacceptable by employers and coworkers, which may immediately lead to termination of employment (Hendricks 2010; McClannahan et al. 2002). Matson et al. (2011) stated that for adults with ASD, in many cases, challenging behaviors have clear antecedents. In the workplace, these antecedents were reported as sensory issues, misunderstanding during conversations, and unanticipated changes in routine schedule (Hurlbutt and Chalmers 2002, 2004; Müller et al. 2003).

Comorbidity Comorbidity is defined as the co-occurrence of two or more diagnoses in the same person (LoVullo and Matson 2009). Schaller and Yang (2005) examined the impact of having a secondary diagnosis of intellectual disability (ID), neurotic disorders, and mental/emotional disorders (e.g., anxiety and depression) to an individual's successful employment. They found that having comorbidity significantly reduced the likelihood of being competitively employed. Other studies demonstrated the negative impact of having a diagnosis of ID (Billstedt et al. 2011; Cederlund et al. 2008; Farley et al. 2009; Larsen and Mouridsen 1997). Howlin et al.'s (2000, 2004, 2005) studies showed that individuals without an ID were more likely to achieve better employment outcomes. Rutter et al. (1967) reported that poor employment outcomes were associated with people who had a moderate or severe ID (IQ <50). Chiang et al.'s (2013) study showed that youth who had both ASD and ID were less likely to be employed, compared to those with ASD only. However, one study illustrated an opposite result. Taylor and Seltzer (2011) reported that young adults with ASD without ID were up to three times more likely to be unemployed than their peers who had an ID and ASD. They also found that the absence of ID could be a negative factor for overall improvement in adulthood, compared to those with ASD and ID (Taylor and Seltzer 2010). Despite the relatively small sample of Taylor and Seltzer's $(2010,2011)$ studies, the findings may be accounted for by the absence of adequate services that accommodated the unique needs of individuals with ASD without ID.

Evidence is growing that anxiety disorder is common in individuals with ASD, especially among those with Asperger's and high-functioning ASD (Hillier et al. 2007b; Mannion and Leader 2013). Kuusikko et al. (2008) found that anxiety disorder increased as individuals with ASD became older, while the typically developing adolescents reported a decrease of anxiety. Taylor and Seltzer (2011) reported that $24 \%$ of the transition youth were having an anxiety disorder. Baldwin et al. (2014) found that $68 \%$ of adults with Asperger's and high-functioning ASD were having an anxiety disorder. All the participants in Hurlbutt and Chalmers' (2004) study experienced a high level of anxiety during employment, and some of them were also put on medication for anxiety. Gillott and Standen (2007) illustrated that unanticipated changes and sensory stimuli were the major sources of stress in the workplaces for people on the spectrum, while coworkers might be unaware of these issues. Hurlbutt and Chalmers (2004) also demonstrated that when individuals with ASD encountered difficulties in the workplace and were without support, their levels of stress and anxiety largely increased.

Educational Level The relationship between educational level and employment for people with ASD is ambiguous at best (Holwerda et al. 2012). Lotter (1974) reported that less than 7 years of education usually led to poor employment outcomes. Lawer et al. (2009) indicated that people with lower than high school education experienced more difficulty finding employment than those who had a higher educational level. Migliore et al. (2012) found that post-secondary education not only correlated with a higher employment rate but also contributed to longer working hours and higher wages. Lawer et al.'s (2009) study indicated that having less than a high school education might increase the risks of being denied for vocational services. Researchers stated that higher 
educational levels, especially post-secondary education, give individuals opportunities to learn the skills necessary to cope with employment (Berney 2004), and add an outstanding asset to their resume (Schall et al. 2012).

Interestingly, some studies showed that college does not guarantee adequate employment in a relevant field and that college graduates with ASD are still unemployed or underemployed (Hurlbutt and Chalmers 2002, 2004). This situation is especially common among individuals with highfunctioning ASD and Asperger's. Howlin (2003) and Howlin et al. (2005) reported that achieving a college or above level of education did not necessarily lead to improved employment outcomes. Baldwin et al. (2014) reported that $45 \%$ of the adults on the spectrum were overeducated for the job they were performing.

\section{External Challenging Factors}

Employers' Attitudes It is important to consider employers' characteristics and how they interact with individuals with ASD, because these factors ultimately determine whether people get a job and how he/she sustains the position (Vornholt et al. 2013; Wilczynski et al. 2013). López and Keenan (2014) conducted a survey that demonstrated that "lack of appropriate understanding from employers and coworkers" is one of the biggest barriers to successful employment. Nesbitt (2000) investigated 69 employers and found that those who were not hiring people on the spectrum ( $58 \%$ of the total participants) shared some common features, such as being focused on an employee's ability to work in an established way, emphasis on an employee's ability to adapt, concern for potential negative effects, and less open to new information. Richards (2012) indicated that employers' reticence and resistance toward workplace adjustments related to employees' disability, and the reluctance of involving third parties' support, would eventually lead to the termination of employment for people with Asperger's. All the studies emphasized that future research should be conducted to examine the employers' as well as the co-workers' attitudes and perceived concerns about hiring and supporting people with ASD. It was suggested that appropriate autism awareness training would help mediate the cost-benefit-oriented decision (López and Keenan 2014; Nesbitt 2000; Richards 2012).

Vocational Services The inconsistent or limited access to adequate vocational services is another identified challenge to successful employment. As a lifelong condition, consistent provision of necessary support and services is required. Studies have shown that people with ASD can benefit from vocational interventions when appropriate services are provided (Howlin 2013; Lugas et al. 2010; Patterson and Rafferty 2001). However, the current situation is far from satisfactory. Vocational services for people with ASD are inadequate, both in quantity and in quality (Howlin 2013; Taylor et al. 2012).

In the USA, the Rehabilitation Act highly emphasizes the provision of VR services for people with disabilities, largely to extend their abilities for working and living independently. Although the VR system has a long history of serving people with physical disabilities, it has not been prepared for meeting the needs of emerging service seekers with ASD (Burgess and Cimera 2014; Howlin 2013; Taylor and Seltzer 2011; Wehman et al. 2014). A rapidly increasing number of transition youth and adults with ASD have started seeking services from the VR system in recent years (Cimera and Cowan 2009; Migliore et al. 2014). However, Lawer et al. (2009) indicated that many individuals with ASD are more likely to be denied by the VR system than those with other disabilities, because they are considered to be unable to benefit from the services. Taylor and Seltzer's (2010) study showed that many people on the spectrum did not receive services due to long waiting lists. Besides VR services, other existing vocational programs have also been reported as inaccessible to individuals with ASD. Even though some programs are designed for people with developmental disabilities, people with ASD are still declined from receiving services as they do not have diagnoses of intellectual disability (Müller et al. 2003; Taylor and Seltzer 2011). Other studies have indicated that vocational services are not provided consistently due to geographical and funding issues (Health Service Executive 2012; Ridley and Hunter 2006). These together contribute to a significant loss of services when individuals graduate from school (Shattuck et al. 2011; Taylor and Seltzer 2010; Test et al. 2014; Wehman et al. 2014).

For those who receive the services, the quality of services remains a concern. Berney (2004) reported that individuals with high-functioning ASD and Asperger's found themselves "in a maze guided by vocational specialists," who were limited with knowledge of the condition. Lattimore et al. (2006) and Lawer et al. (2009) both indicated that VR service providers rarely recognize the unique needs of on-the-job supports among those on the spectrum. The provision of this service ranged between 31 and $45 \%$ (Lawer et al. 2009; Migliore et al. 2012; Test et al. 2014). Taylor et al.'s (2012) systematic review concluded that due to the poor methodological quality of existing studies, there is no credible evidence for a specific vocational approach for youth and adults with ASD.

Disability-Related Benefits Migliore et al. (2012) reported that receiving disability-related allowances or medical benefits significantly reduced the likelihood of being successfully employed for people with ASD. For those employed, receiving disability-related benefits was highly correlated with fewer working hours and less earnings. Although Migliore et al.'s (2012) study was the only one to investigate the effect of 
disability-related benefits, the results seem compelling for further research. The study indicated that for people who had negative employment experience for a long time, choosing low-paying jobs or not to work on purpose could be out of concern for securing their disability benefits. This effect has been widely examined in people with other chronic disabilities (Chan et al. 2008; Dutta et al. 2008; Jung and Bellini 2011).

Family Socioeconomic Status Family socioeconomic status (SES) is another factor that has recently been examined. Studies have showed that young adults with ASD whose families had lower incomes were more at risk of having no employment or formal services after they exited the school system (Shattuck et al. 2012, 2011; Taylor and Mailick 2013; Taylor and Seltzer 2010). A plausible reason of this disparity could be because lower family SES is usually associated with fewer resources and opportunities, as well as with less access to services (Shattuck et al. 2012; Taylor and Seltzer 2010).

\section{Strategies for Successful Employment}

Although from a methodological perspective, the majority of existing vocational interventions and services are considered as having limited empirical evidence of effectiveness (Taylor et al. 2012; Westbrook et al. 2012); the current literature has provided conceptualized strategies for further investigation.

\section{Supported Employment}

Supported employment is a comprehensive scheme for assisting people with severe disability to achieve and maintain employment in competitive work settings (Rusch and Hughes 1989; Wehman et al. 1997). Mawhood and Howlin (1999) indicated that supported employment adequately meets the needs of individuals with ASD, because it provides customized, intensive, and ongoing support.

In the mid-1980s, several case reports illustrated the positive impact of supported employment in reducing challenging behaviors and handling work-related problems for individuals with ASD (Smith and Coleman 1986; Wehman and Kregel 1988). Mawhood and Howlin (1999) conducted a quasiexperimental study which reported significant positive employment outcomes for adults with ASD who received supported employment services, compared to those who did not. This study also emphasized the importance of job match and, if indicated, the high initial cost of service schemes. Howlin et al. (2005) continued to track employed cases over an 8-year period, finding that ongoing employment supports yielded long-term benefits for the service users and their employers. However, financial deficits of the programs continued to be a big concern. Recently, Mavranezouli et al. (2013) conducted a study which specifically examined the cost-effectiveness of supported employment for adults with ASD; they found that although the initial costs were higher for these services, they were reduced over time. The authors concluded that, ultimately, supported employment is more beneficial for the individuals in all aspects, when compared to standard care.

Hillier et al. (2007b) examined the positive impact of longterm supported employment services in securing jobs and raising salaries for people with ASD. They carefully concluded that success was only at entry-level employment. GarcíaVillamisar and his colleagues conducted a series of studies that illustrated the positive impacts of supported employment on cognitive performance, autistic symptoms, and quality of life for individuals with ASD (García-Villamisar and Hughes 2007; García-Villamisar et al. 2000, 2002). Schaller and Yang's (2005) study demonstrated that individuals receiving supported employment services had a statistically higher employment rate than their peers who did not receive the services. They also worked for more hours and earned higher wages. Cimera et al. (2012) found that individuals with ASD achieved better employment outcomes and cost significantly less in services, if they did not participate in sheltered workshops prior to enrolling in supported employment.

Although studies have illustrated the promising impacts of supported employment, future research should conduct more robust evidence-based studies of effective service programs. The TEACCH-supported employment program was developed using a structured ASD-specific visual supporting approach; however, it has not been investigated empirically. Keel et al. (1997) reported a job retention rate of $89 \%$ by using the TEACCH scheme, which was quite promising for further investigation. Recently, Wehman and his colleagues introduced a modified supported employment model, Project SEARCH, for young adults with ASD (Wehman et al. 2012). They published the first randomized clinical trial (RCT) study, with strong evidence support for the program. It was reported that $88 \%$ of the treatment participants acquired employment, whereas only $6 \%$ of the control group participants were employed.

\section{Transition Services}

The Individuals with Disabilities Education Act (IDEA) 2004 in the USA recommends that transition services should be provided to all individuals with disabilities, including those with ASD, to facilitate their movement from school to adult life. Its ultimate goal is to ensure that these individuals achieve employment and independent living after graduation (Certo et al. 2008). Many countries (e.g., the USA, the UK, Australia, and Canada) also have recognized the importance of transition programs (Westbrook et al. 2014).

Wehman et al. (2014) suggested that in order to help individuals prepare for their post-school lives, goal-oriented 
transition services must take place before they exit school. Early-initiated services provide longer time for individual preparation and navigation, and young adults with ASD can become more skilled and employable for employment after exiting the school system (Autism Speaks 2012; Chappel and Somers 2010; Hendricks and Wehman 2009). Cimera et al. (2013) analyzed 4-year vocational rehabilitation data and found quite compelling results. The study showed that individuals with ASD who received transition services at age 14 were significantly more likely to be employed than those who received transition services at age 16 . Furthermore, those who received transition services earlier also had higher wages and cost less in services.

A systematic review by Westbrook et al. (2014) indicated that there is a lack of empirical research for transition programs and that future rigorous experimentally designed studies will be needed to determine the effectiveness of the programs. In addition, the authors addressed some promising features of ASD-specific transition services, including behavior-shaping techniques, social skill interventions, and family-centered approaches.

\section{Assistive Technology}

Technology is leading the improvement of daily living skills, such as the independence and employment of people with disabilities (Ramdoss et al. 2012; Schneider 1999; Yeager et al. 2006). During the past few decades, a variety of technologies, such as tactile prompting, picture guiding, audio cuing, video modeling, computeraided instruction, virtual reality, and robotics, have been developed and implemented among individuals with ASD for different training purposes (DiGennaro Reed et al. 2011; Goldsmith and LeBlanc 2004; Hopkins et al. 2011; Parsons 2006).

A large number of existing studies have focused on improving social skills for people with ASD, and they have reported positive results. Successful outcomes were demonstrated in conversational skills (Sherer et al. 2001), emotion understanding (Silver and Oakes 2001), perspective taking (LeBlanc et al. 2003), and functional self-help skills (Shrestha et al. 2013). Although these studies were not conducted in an employment environment, all these social skills are highly relevant in the workplace.

Strickland et al. (2013) recently developed an internetbased training program for social skills that is especially relevant to job searching and job interviews. An embedded virtual reality environment for practicing interview skills was included. Positive results showed that youth who completed the training program demonstrated significantly more effective interview skills than those who did not. Another virtual reality program for interview skills training was developed by Smith et al. (2014). The research indicated that participants in the treatment group greatly improved more on their interview performance than those in the control group. The training program was found easy to use and enjoyable for the individuals.

Hill et al. (2013) introduced iPad as an innovative employment support tool for young adults with ASD. Through training individuals using selected iPad applications to help with organization, scheduling, and social interaction, as well as leisure enjoyment, increased independence and successful employment outcomes were reported among all the participants. The authors suggested that popular consumer devices such as iPad would be more readily adopted by individuals with ASD because they help to diminish potential stigma associated with Assistive Technology (AT) use (Parette and Scherer 2004).

Research has also provided positive results for using AT in work-related behavior training. Studies have explored the usefulness of video modeling and audio cuing in teaching and supporting job task accomplishment in communitybased worksites (Allen et al. 2010a, b, 2012; Bennett et al. 2013a, b; Kellems and Morningstar 2012). Van Laarhoven et al. (2012) demonstrated excellent maintenance of vocational skills by using video modeling supports.

\section{Multidisciplinary Collaboration}

A strong multidisciplinary collaboration is widely emphasized as a crucial strategy for successful employment (Friedman et al. 2013; Test et al. 2014). However, few studies have addressed the critical considerations and configurations of potential partnerships. Chappel and Somers (2010) illustrated a roadmap for specialists in education system who sought to lead the collaborations. They suggested that when supporting students with ASD to achieve their employment goals, education service providers should seek early linkage with VR service providers, enhance the family's and individual's involvement, and prepare for employer training. Mawhood and Howlin (1999) emphasized a close liaison between VR service providers and employers which would allow for exploring possible job opportunities and matching the skills and abilities of the employee with a suitable job. Hillier et al. (2007a) indicated that higher parental involvement and family support could lead to better employment outcomes for individuals with ASD. Self-determination as well as autonomy of individuals on the spectrum are also important in the collaboration (Carter et al. 2012; Test et al. 2014).

Therefore, a comprehensive model with collaboration of all partners would potentially lead to effectiveness and efficiency in understanding and solving employment-related problems, and thus to supporting overall vocational success (Certo et al. 2008; Hillier et al. 2007a, b; Nicholas et al. 2014; Shattuck and Roux 2014). Project SEARCH is such a model that involves all of the following components and encourages all 
partners to collaborate instead of co-exist. This particular model is operated in a way that the individual with ASD and family members identify their personalized employment goals and participate in vocational assessments and internships. The local education agency provides a teacher and an adequate number of instructional assistants to implement the senior year IEP of student interns in the program. The state VR agency provides funding and supervision for job coaching services that are provided throughout the final year of school in the internships. The community rehabilitation program provides a behavior/autism specialist as job coach to assess student interests, develop and supervise internships, and provide on-site job coaching during the school day. The employer provides internship sites for the individuals with ASD. The co-workers attend intensive staff training in ASD (Wehman et al. 2013). The authors highlighted multidisciplinary collaboration as one of the key features for overall success (Wehman et al. 2012, 2013, 2014).

\section{Implications}

After reviewing the existing literature, several important implications for future clinical practice and research emerge from this study.

\section{Future Clinical Practices}

Customized employment services should be emphasized for individuals with ASD. The countless permutations and combinations of internal and external challenges make employment an especially baffling situation for adults with ASD. Current emerging services have tried to address the social deficits by providing job-related skills training for these adults. However, ASD-specific strategies should be incorporated. In addition, other factors, such as comorbidity, family supports, individualized assistive technology, and balance in using disability-related benefits, should also be taken into consideration when developing the service plan.

The strength-based approach should be implemented when matching the jobs for adults with ASD. It is important for service providers to help individuals translating their unique features into employment benefits, such as being detail-oriented and having preference for repetitive tasks, high concentration, and concrete thinking. This will also help the potential employers to know better about the individuals.

A dynamic service scheme should be adopted based on collaboration among service users, the education system, and the vocational service system, as well as employers. Positive interactions between all stakeholders should be encouraged and should lead to a better outcomes.
Future Research

Future research should include further investigation into employment outcomes for all individuals across the spectrum. Current research is not representative, because they only investigated people who had access to services. However, large groups of people are still outside the service system. Therefore, there is a need for large population-based studies of employment outcomes for people with ASD.

A reliable vocational outcome measure should be developed and used for employment outcome studies. Employment rates, earnings, and weekly working hours illustrate important aspects of employment outcomes. However, more detailed information about vocational activities should be captured for better evaluation of the outcomes. For instance, an individual's quality of life and level of job satisfaction should also be taken into consideration when measuring employment.

An evidence-based, integrative framework for investigating employment-related challenges faced by individuals with ASD is required. We suggest that future research should incorporate the World Health Organization's International Classification of Functioning, Disability and Health (ICF) model, for a comprehensive understanding of both the internal and the external factors, and how they interact and impact an individual's employment in a dynamic functional way. This will allow us to develop, evaluate, and implement vocational intervention strategies in order to enhance optimal employment outcomes for this population.

Specific service schemes for people with ASD have been proposed during the past few years, but the majority of them have not been empirically examined. Future studies should be conducted to investigate the effectiveness of these service programs. Given the lack of empirical evidence, conceptualized introductions of new schemes with promising strategies as well as other strategies, which have been demonstrated effective in populations with similar disabilities, are still necessary.

\section{Conclusion}

This literature review presented detailed information on research about employment for individuals with ASD. We investigated studies about employment outcomes, challenges to successful employment, and related strategies. Overall, our findings demonstrate that adults with ASD are in a poor employment situation with unserved needs. Clinical service providers should be aware of individuals' unique characteristics and employment needs. Research should be conducted to interpret better the situation and to help to improve the service provision. 


\section{References}

Allen, K. D., Burke, R. V., Howard, M. R., Wallace, D. P., \& Bowen, S. L. (2012). Use of audio cuing to expand employment opportunities for adolescents with autism spectrum disorders and intellectual disabilities. Journal of Autism and Developmental Disorders, 42(11), 2410-2419. doi:10.1007/s10803-012-1519-7.

Allen, K. D., Wallace, D. P., Greene, D. J., Bowen, S. L., \& Burke, R. V. (2010a). Community-based vocational instruction using videotaped modeling for young adults with autism spectrum disorders performing in air-inflated mascots. Focus on Autism and Other Developmental Disabilities, 25(3), 186-192. doi:10.1177/ 1088357610377318.

Allen, K. D., Wallace, D. P., Renes, D., Bowen, S. L., \& Burke, R. V. (2010b). Use of video modeling to teach vocational skills to adolescents and young adults with autism spectrum disorders. Education \& Treatment of Children, 33(3), 339-349.

Autism Speaks. (2012, July 25). Why a transition plan? Retrieved June 16, 2014, from http://www.autismspeaks.org/family-services/toolkits/transition-tool-kit/why-transition-plan

Baldwin, S., Costley, D., \& Warren, A. (2014). Employment activities and experiences of adults with high-functioning autism and Asperger's disorder. Journal of Autism and Developmental Disorders, 1-10. doi:10.1007/s10803-014-2112-z

Bennett, K. D., \& Dukes, C. (2013). Employment instruction for secondary students with autism spectrum disorder: a systematic review of the literature. Education and Training in Autism and Developmental Disabilities, 48(1), 67-75.

Bennett, K. D., Ramasamy, R., \& Honsberger, T. (2013a). Further examination of covert audio coaching on improving employment skills among secondary students with autism. Journal of Behavioral Education, 22(2), 103-119. doi:10.1007/s10864-013-9168-2.

Bennett, K. D., Ramasamy, R., \& Honsberger, T. (2013b). The effects of covert audio coaching on teaching clerical skills to adolescents with autism spectrum disorder. Journal of Autism and Developmental Disorders, 43(3), 585-593. doi:10.1007/s10803-012-1597-6.

Berney, T. (2004). Asperger syndrome from childhood into adulthood. Advances in Psychiatric Treatment, 10(5), 341-351. doi:10.1192/ apt.10.5.341.

Billstedt, E., Gillberg, I. C., \& Gillberg, C. (2011). Aspects of quality of life in adults diagnosed with autism in childhood: a populationbased study. Autism, 15(1), 7-20. doi:10.1177/1362361309346066.

Bolman, W. M. (2008). Brief report: 25-year follow-up of a highfunctioning autistic child. Journal of Autism and Developmental Disorders, 38(1), 181-183. doi:10.1007/s10803-007-0362-8.

Brugha, T. S., McManus, S., Bankart, J., Scott, F., Purdon, S., Smith, J., \& Meltzer, H. (2011). Epidemiology of autism spectrum disorders in adults in the community in England. Archives of General Psychiatry, 68(5), 459-465. doi:10.1001/archgenpsychiatry.2011.38.

Burgess, S., \& Cimera, R. E. (2014). Employment outcomes of transitionaged adults with autism spectrum disorders: a state of the state's report. American Journal on Intellectual and Developmental Disabilities, 119(1), 64-83. doi:10.1352/1944-7558-119.1.64.

Burt, D. B., Fuller, S. P., \& Lewis, K. R. (1991). Brief report: Competitive employment of adults with autism. Journal of Autism and Developmental Disorders, 21(2), 237-242. doi:10.1007/ BF02284763.

Cameto, R. (2003). Findings from the national longitudinal transition study-2(NLTS2): collecting and utilizing postschool outcome data to improve transition programs and services at the national, state and local levels. Menlo Park: SRI International.

Capo, L. (2001). Autism, employment, and the role of occupational therapy. Work, 16(3), 201-207.

Carter, E. W., Austin, D., \& Trainor, A. A. (2012). Predictors of postschool employment outcomes for young adults with severe disabilities. Journal of Disability Policy Studies, 23(1), 50-63. doi: 10.1177/1044207311414680.

Centers for Disease Control and Prevention (CDC). (2000). Facts About ASDs. Retrieved July 1, 2014, from http://www.cdc.gov/ncbddd/ autism/data.html.

Centers for Disease Control and Prevention (CDC). (2014). Press release: CDC estimates 1 in 68 children has been identified with autism spectrum disorder. Retrieved April 29, 2014, from http://www.cdc. gov/media/releases/2014/p0327-autism-spectrum-disorder.html

Cederlund, M., Hagberg, B., Billstedt, E., Gillberg, I., \& Gillberg, C. (2008). Asperger syndrome and autism: a comparative longitudinal follow-up study more than 5 years after original diagnosis. Journal of Autism \& Developmental Disorders, 38(1), 72-85.

Certo, N. J., Brown, L., Courey, S., Belanger, D., Luecking, R. G., \& Murphy, S. (2008). Seamless transition and long-term support for individuals with severe intellectual disabilities. Research \& Practice for Persons with Severe Disabilities, 33(3), 85-95.

Chan, F., Strauser, D., Silva Cardoso, E., Xi Zheng, L., Chan, J. Y. C., \& Feuerstein, M. (2008). State vocational services and employment in cancer survivors. Journal of Cancer Survivorship, 2(3), 169-178. doi:10.1007/s11764-008-0057-y.

Chappel, S. L., \& Somers, B. C. (2010). Employing persons with autism spectrum disorders: a collaborative effort. Journal of Vocational Rehabilitation, 32(2), 117-124. doi:10.3233/JVR-2010-0501.

Chiang, H.-M., Cheung, Y. K., Li, H., \& Tsai, L. Y. (2013). Factors associated with participation in employment for high school leavers with autism. Journal of Autism and Developmental Disorders, 43(8), 1832-1842. doi:10.1007/s10803-012-1734-2.

Cimera, R. E., Burgess, S., \& Wiley, A. (2013). Does providing transition services early enable students with ASD to achieve better vocational outcomes as adults? Research and Practice for Persons with Severe Disabilities, 38(2), 88-93.

Cimera, R. E., \& Cowan, R. J. (2009). The costs of services and employment outcomes achieved by adults with autism in the US. Autism, 13(3), 285-302. doi:10.1177/1362361309103791.

Cimera, R. E., Wehman, P., West, M., \& Burgess, S. (2012). Do sheltered workshops enhance employment outcomes for adults with autism spectrum disorder? Autism, 16(1), 87-94. doi:10.1177/ 1362361311408129.

DiGennaro Reed, F. D., Hyman, S. R., \& Hirst, J. M. (2011). Applications of technology to teach social skills to children with autism. Research in Autism Spectrum Disorders, 5(3), 1003-1010. doi:10.1016/j.rasd. 2011.01.022.

Dutta, A., Gervey, R., Chan, F., Chou, C.-C., \& Ditchman, N. (2008). Vocational rehabilitation services and employment outcomes for people with disabilities: a United States study. Journal of Occupational Rehabilitation, 18(4), 326-334. doi:10.1007/ s10926-008-9154-z.

Eaves, L., \& Ho, H. (2008). Young adult outcome of autism spectrum disorders. Journal of Autism and Developmental Disorders, 38(4), 739-747.

Farley, M. A., McMahon, W. M., Fombonne, E., Jenson, W. R., Miller, J., Gardner, M., \& Coon, H. (2009). Twenty-year outcome for individuals with autism and average or near-average cognitive abilities. Autism Research, 2(2), 109-118. doi:10.1002/aur.69.

Fleming, A. R., Fairweather, J. S., \& Leahy, M. J. (2013). Quality of life as a potential rehabilitation service outcome: the relationship between employment, quality of life, and other life areas. Rehabilitation Counseling Bulletin, 57(1), 9-22. doi:10.1177/ 0034355213485992.

Friedman, N. D., Warfield, M. E., \& Parish, S. L. (2013). Transition to adulthood for individuals with autism spectrum disorder: current issues and future perspectives. Neuropsychiatry, 3(2), 181-192. doi: 10.2217/npy.13.13.

García-Villamisar, D., \& Hughes, C. (2007). Supported employment improves cognitive performance in adults with autism. Journal of 
Intellectual Disability Research, 51(2), 142-150. doi:10.1111/j. 1365-2788.2006.00854.x.

García-Villamisar, D., Ross, D., \& Wehman, P. (2000). Clinical differential analysis of persons with autism in a work setting: a follow-up study. Journal of Vocational Rehabilitation, 14(3), 183-185.

García-Villamisar, D., Wehman, P., \& Navarro, M. D. (2002). Changes in the quality of autistic people's life that work in supported and sheltered employment. A 5-year follow-up study. Journal of Vocational Rehabilitation, 17(4), 309-312.

Gerhardt, P. F., \& Lainer, I. (2011). Addressing the needs of adolescents and adults with autism: a crisis on the horizon. Journal of Contemporary Psychotherapy, 41(1), 37-45. doi:10.1007/s10879010-9160-2.

Giarelli, E., Ruttenberg, J., \& Segal, A. (2013). Bridges and barriers to successful transitioning as perceived by adolescents and young adults with asperger syndrome. Journal of Pediatric Nursing, 28(6), 563-574. doi:10.1016/j.pedn.2012.12.010.

Gillott, A., \& Standen, P. J. (2007). Levels of anxiety and sources of stress in adults with autism. Journal of Intellectual Disabilities, 11(4), 359-370. doi:10.1177/1744629507083585.

Goldsmith, T. R., \& LeBlanc, L. A. (2004). Use of technology in interventions for children with autism. Journal of Early and Intensive Behavior Intervention, 1(2), 166-178.

Hagner, D., \& Cooney, B. F. (2005). "I do that for everybody": supervising employees with autism. Focus on Autism and Other Developmental Disabilities, 20(2), 91-97. doi:10.1177/ 10883576050200020501.

Health Service Executive. (2012). National review of autism services: Past, present and way forward. Retrieved from www.fedvol.ie/ fileupload/Next\%20Steps/autismreview2012.pdf

Hendricks, D. (2010). Employment and adults with autism spectrum disorders: challenges and strategies for success. Journal of Vocational Rehabilitation, 32(2), 125-134. doi:10.3233/JVR2010-0502.

Hendricks, D., \& Wehman, P. (2009). Transition from school to adulthood for youth with autism spectrum disorders: review and recommendations. Focus on Autism and Other Developmental Disabilities, 24(2), 77-88. doi:10.1177/ 1088357608329827.

Hill, D. A., Belcher, L., Brigman, H. E., Renner, S., \& Stephens, B. (2013). The Apple iPad ${ }^{\mathrm{TM}}$ as an innovative employment support for young adults with autism spectrum disorder and other developmental disabilities. Journal of Applied Rehabilitation Counseling, 44(1), $28-37$.

Hillier, A., Campbell, H., Mastriani, K., Izzo, M. V., Kool-Tucker, A. K., Cherry, L., \& Beversdorf, D. Q. (2007a). Two-year evaluation of a vocational support program for adults on the autism spectrum. Career Development for Exceptional Individuals, 30(1), 35-47. doi:10.1177/08857288070300010501.

Hillier, A., Fish, T., Cloppert, P., \& Beversdorf, D. Q. (2007b). Outcomes of a social and vocational skills support group for adolescents and young adults on the autism spectrum. Focus on Autism and Other Developmental Disabilities, 22(2), 107-115. doi:10.1177/ 10883576070220020201.

Holwerda, A., Klink, J., Groothoff, J., \& Brouwer, S. (2012). Predictors for work participation in individuals with an autism spectrum disorder: a systematic review. Journal of Occupational Rehabilitation, 22(3), 333-352. doi:10.1007/s10926-011-9347-8.

Hopkins, I. M., Gower, M. W., Perez, T. A., Smith, D. S., Amthor, F. R., Wimsatt, F. C., \& Biasini, F. J. (2011). Avatar assistant: improving social skills in students with an ASD through a computer-based intervention. Journal of Autism and Developmental Disorders, 4l(11), 1543-1555. doi:10.1007/s10803-011-1179-z.

Howlin, P. (2000). Outcome in adult life for more able individuals with autism or asperger syndrome. Autism, 4(1), 63-83. doi:10.1177/ 1362361300004001005 .
Howlin, P. (2003). Outcome in high-functioning adults with autism with and without early language delays: implications for the differentiation between autism and asperger syndrome. Journal of Autism and Developmental Disorders, 33(1), 3-13.

Howlin, P. (2013). Social disadvantage and exclusion: adults with autism lag far behind in employment prospects. Journal of the American Academy of Child \& Adolescent Psychiatry, 52(9), 897-899.

Howlin, P., Alcock, J., \& Burkin, C. (2005). An 8 year follow-up of a specialist supported employment service for high-ability adults with autism or asperger syndrome. Autism, 9(5), 533-549. doi:10.1177/ 1362361305057871

Howlin, P., Goode, S., Hutton, J., \& Rutter, M. (2004). Adult outcome for children with autism. Journal of Child Psychology and Psychiatry, and Allied Disciplines, 45(2), 212-229.

Howlin, P., Mawhood, L., \& Rutter, M. (2000). Autism and developmental receptive language disorder-a follow-up comparison in early adult life. II: social, behavioural, and psychiatric outcomes. Journal of Child Psychology \& Psychiatry \& Allied Disciplines, 41(5), 561578.

Hurlbutt, K., \& Chalmers, L. (2002). Adults with autism speak out perceptions of their life experiences. Focus on Autism and Other Developmental Disabilities, 17(2), 103-111. doi:10.1177/ 10883576020170020501.

Hurlbutt, K., \& Chalmers, L. (2004). Employment and adults with asperger syndrome. Focus on Autism \& Other Developmental Disabilities, 19(4), 215-222.

Jung, Y., \& Bellini, J. L. (2011). Predictors of employment outcomes for vocational rehabilitation consumers with HIV/AIDS: 2002-2007. Rehabilitation Counseling Bulletin, 54(3), 142-153. doi:10.1177/ 0034355210392241

Kanner, L. (1973). Childhood psychosis: initial studies and new insights. Washington D.C.: John Wiley \& Sons.

Keel, J., Mesibov, G., \& Woods, A. (1997). TEACCH-supported employment program. Journal of Autism \& Developmental Disorders, 27(1), 3-9.

Kellems, R. O., \& Morningstar, M. E. (2012). Using video modeling delivered through iPods to teach vocational tasks to young adults with autism spectrum disorders. Career Development and Transition for Exceptional Individuals, 35(3), 155-167. doi:10. 1177/0885728812443082.

Kobayashi, R., Murata, T., \& Yoshinaga, K. (1992). A follow-up study of 201 children with autism in Kyushu and Yamaguchi areas, Japan. Journal of Autism and Developmental Disorders, 22(3), 395-411. doi:10.1007/BF01048242.

Kuusikko, S., Pollock-Wurman, R., Jussila, K., Carter, A. S., Mattila, M.L., Ebeling, H., \& Moilanen, I. (2008). Social anxiety in highfunctioning children and adolescents with autism and asperger syndrome. Journal of Autism and Developmental Disorders, 38(9), 1697-1709. doi:10.1007/s10803-008-0555-9.

Larsen, F. W., \& Mouridsen, S. E. (1997). The outcome in children with childhood autism and asperger syndrome originally diagnosed as psychotic: a 30-year follow-up study of subjects hospitalized as children. European Child \& Adolescent Psychiatry, 6(4), 181-190.

Lattimore, L. P., Parsons, M. B., \& Reid, D. H. (2006). Enhancing job-site training of supported workers with autism: a reemphasis on simulation. Journal of Applied Behavior Analysis, 39(1), 91-102. doi:10. 1901/jaba. 2006.154-04.

Lawer, L., Brusilovskiy, E., Salzer, M. S., \& Mandell, D. S. (2009). Use of vocational rehabilitative services among adults with autism. Journal of Autism and Developmental Disorders, 39(3), 487-494. doi:10.1007/s10803-008-0649-4.

LeBlanc, L. A., Coates, A. M., Daneshvar, S., Charlop-Christy, M. H., Morris, C., \& Lancaster, B. M. (2003). Using video modeling and reinforcement to teach perspective-taking skills to children with autism. Journal of Applied Behavior Analysis, 36(2), 253-257. doi:10.1901/jaba. 2003.36-253. 
López, B., \& Keenan, L. (2014). Barriers to employment in autism: future challenges to implementing the Adult Autism Strategy. Autism Research Network. Retrieved from http://www.autismrpphub.org/ sites/default/files/articles/employment_report.pdf

Lotter, V. (1974). Social adjustment and placement of autistic children in Middlesex: a follow-up study. Journal of Autism and Childhood Schizophrenia, 4(1), 11-32. doi:10.1007/BF02104997.

LoVullo, S. V., \& Matson, J. L. (2009). Comorbid psychopathology in adults with autism spectrum disorders and intellectual disabilities. Research in Developmental Disabilities, 30(6), 1288-1296.

Lugas, J., Timmons, J., \& Smith, F. A. (2010). Vocational rehabilitation services received by youth with autism: are they associated with an employment outcome? Research to Practice Brief, Issue No. 48. Boston, MA: Institute for Community Inclusion, University of Massachusetts Boston.

Mannion, A., \& Leader, G. (2013). Comorbidity in autism spectrum disorder: a literature review. Research in Autism Spectrum Disorders, 7(12), 1595-1616. doi:10.1016/j.rasd.2013.09.006.

Matson, J. L., Sipes, M., Fodstad, J. C., \& Fitzgerald, M. E. (2011). Issues in the management of challenging behaviours of adults with autism spectrum disorder. CNS Drugs, 25(7), 597-606.

Mavranezouli, I., Megnin-Viggars, O., Cheema, N., Howlin, P., BaronCohen, S., \& Pilling, S. (2013). The cost-effectiveness of supported employment for adults with autism in the United Kingdom. Autism, 1-10. doi:10.1177/1362361313505720.

Mawhood, L., \& Howlin, P. (1999). The outcome of a supported employment scheme for high-functioning adults with autism or asperger syndrome. Autism, 3(3), 229-254. doi:10.1177/ 1362361399003003003.

McClannahan, L. E., MacDuff, G. S., \& Krantz, P. J. (2002). Behavior analysis and intervention for adults with autism. Behavior Modification, 26(1), 9-26. doi:10.1177/0145445502026001002.

Migliore, A., Butterworth, J., \& Zalewska, A. (2014). Trends in vocational rehabilitation services and outcomes of youth with autism: 2006-2010. Rehabilitation Counseling Bulletin, 57(2), 80-89. doi: 10.1177/0034355213493930.

Migliore, A., Timmons, J., Butterworth, J., \& Lugas, J. (2012a). Predictors of employment and postsecondary education of youth with autism. Rehabilitation Counseling Bulletin, 55(3), 176-184. doi:10.1177/0034355212438943.

Migliore, A., \& Zalewska, A. (2012). What are the employment experiences of youth with autism after high school? DataNote Series, DataNote 40. Boston, MA: University of Massachusetts Boston, Institute for Community Inclusion. Retrieved from http://www. communityinclusion.org/article.php?article id $=341$

Müller, E., Schuler, A., Burton, B. A., \& Yates, G. B. (2003). Meeting the vocational support needs of individuals with asperger syndrome and other autism spectrum disabilities. Journal of Vocational Rehabilitation, 18(3), 163-175.

Nesbitt, S. (2000). Why and why not? factors influencing employment for individuals with asperger syndrome. Autism, 4(4), 357-369. doi:10. 1177/1362361300004004002.

Newman, L., Wagner, M., Cameto, R., Knokey, A.-M., \& Shaver, D. (2010). Comparisons across time of the outcomes of youth with disabilities up to 4 years after high school: A report of findings from the National Longitudinal Transition Study (NLTS) and the National Longitudinal Transition Study-2 (NLTS2). NCSER 2010-3008. National Center for Special Education Research. Retrieved from http://files.eric.ed.gov/ fulltext/ED512149.pdf

Newman, L., Wagner, M., Knokey, A.-M., Marder, C., Nagle, K., Shaver, D., \& Wei, X. (2011). The post-high school outcomes of young adults with disabilities up to 8 years after high school: a report from the National Longitudinal Transition Study-2 (NLTS2). NCSER 2011-3005. National Center for Special Education Research. Retrieved from http://eric.ed.gov/?id=ED524044
Nicholas, D. B., Attridge, M., Zwaigenbaum, L., \& Clarke, M. (2014). Vocational support approaches in autism spectrum disorder: a synthesis review of the literature. Autism, published online before print. doi: $10.1177 / 1362361313516548$

Parette, P., \& Scherer, M. (2004). Assistive technology use and stigma. Education and Training in Developmental Disabilities, 39(3), 217 226.

Parsons, L. D. (2006). Using video to teach social skills to secondary students with autism. (cover story). Teaching Exceptional Children, $39(2), 32-38$.

Patterson, A., \& Rafferty, A. (2001). Making it to work: towards employment for the young adult with autism. International Journal of Language \& Communication Disorders, 36, 475-480.

Ramdoss, S., Lang, R., Fragale, C., Britt, C., O'Reilly, M., Sigafoos, J., Didden, R., et al. (2012). Use of computer-based interventions to promote daily living skills in individuals with intellectual disabilities: A systematic review. Journal of Developmental and Physical Disabilities, 24(2), 197-215.

Richards, J. (2012). Examining the exclusion of employees with asperger syndrome from the workplace. Personnel Review, 41(5), 630-646. doi:10.1108/00483481211249148.

Ridley, J., \& Hunter, S. (2006). The development of supported employment in Scotland. Journal of Vocational Rehabilitation, 25(1), 57-68.

Roux, A. M., Shattuck, P. T., Cooper, B. P., Anderson, K. A., Wagner, M., \& Narendorf, S. C. (2013). Postsecondary employment experiences among young adults with an autism spectrum disorder. Journal of the American Academy of Child \& Adolescent Psychiatry, 52(9), 931-939. doi:10.1016/j.jaac.2013.05.019.

Rumsey, J. M., Rapoport, J. L., \& Sceery, W. R. (1985). Autistic children as adults: psychiatric, social, and behavioral outcomes. Journal of the American Academy of Child Psychiatry, 24(4), 465-473. doi:10. 1016/S0002-7138(09)60566-5.

Rusch, F. R., \& Hughes, C. (1989). Overview of supported employment. Journal of Applied Behavior Analysis, 22(4), 351-363. doi:10.1901/ jaba. 1989.22-351.

Rutter, M., Greenfeld, D., \& Lockyer, L. (1967). A five to 15 year followup study of infantile psychosis II: social and behavioural outcome. The British Journal of Psychiatry, 113(504), 1183-1199. doi:10. 1192/bjp.113.504.1183.

Sanford, C., Newman, L., Wagner, M., Cameto, R., Knokey, A.-M., \& Shaver, D. (2011). The post-high school outcomes of young adults with disabilities up to 6 years after high school: key findings from the National Longitudinal Transition Study-2 (NLTS2).NCSER 2011-3004. National Center for Special Education Research. Retrieved from http://files.eric.ed.gov/fulltext/ED523539.pdf.

Schall, C. (2010). Positive behavior support: supporting adults with autism spectrum disorders in the workplace. Journal of Vocational Rehabilitation, 32(2), 109-115. doi:10.3233/JVR-2010-0500.

Schall, C., Wehman, P., \& McDonough, J. (2012). Transition from school to work for students with autism spectrum disorders: understanding the process and achieving better outcomes. Pediatric Clinics of North America, 59(1), 189-202. doi:10.1016/j.pcl.2011.10.009.

Schaller, J., \& Yang, N. K. (2005). Competitive employment for people with autism: correlates of successful closure in competitive and supported employment. Rehabilitation Counseling Bulletin, 49(1), 4-16. doi:10.1177/00343552050490010201.

Schneider, M. (1999). Achieving greater independence through assistive technology, job accommodation and supported employment. Journal of Vocational Rehabilitation, 12, 159-164.

Shattuck, P. T., Narendorf, S. C., Cooper, B., Sterzing, P. R., Wagner, M., \& Taylor, J. L. (2012). Postsecondary education and employment among youth with an autism spectrum disorder. Pediatrics, 129(6), 1042-1049. doi:10.1542/peds. 2011-2864.

Shattuck, P. T., \& Roux, A. M. (2014). Commentary on employment supports research. Autism, published online before print. doi:10. $1177 / 1362361313518996$ 
Shattuck, P. T., Seltzer, M. M., Greenberg, J. S., Orsmond, G. I., Bolt, D., Kring, S., \& Lord, C. (2007). Change in autism symptoms and maladaptive behaviors in adolescents and adults with an autism spectrum disorder. Journal of Autism and Developmental Disorders, 37(9), 1735-1747. doi:10.1007/s10803-006-0307-7.

Shattuck, P. T., Wagner, M., Narendorf, S., Sterzing, P., \& Hensley, M. (2011). Post-high school service use among young adults with an autism spectrum disorder. Archives of Pediatrics \& Adolescent Medicine, 165(2), 141-146. doi:10.1001/archpediatrics.2010.279.

Sherer, M., Pierce, K. L., Paredes, S., Kisacky, K. L., Ingersoll, B., \& Schreibman, L. (2001). Enhancing conversation skills in children with autism via video technology which is better, "self" or "other" as a model? Behavior Modification, 25(1), 140-158.

Shrestha, A., Angelika, \& Moore, D. (2013). Using point-of-view video modeling and forward chaining to teach a functional self-help skill to a child with autism. Journal of Behavioral Education, 22(2), 157 167. doi:10.1007/s10864-012-9165-x.

Silver, M., \& Oakes, P. (2001). Evaluation of a new computer intervention to teach people with autism or asperger syndrome to recognize and predict emotions in others. Autism, 5(3), 299 316.

Smith, M. D., \& Coleman, D. (1986). Managing the behavior of adults with autism in the job setting. Journal of Autism and Developmental Disorders, 16(2), 145-154. doi:10.1007/BF01531726.

Smith, M. J., Ginger, E. J., Wright, K., Wright, M. A., Taylor, J. L., Humm, L. B., ... Fleming, M. F. (2014). Virtual reality job interview training in adults with autism spectrum disorder. Journal of Autism and Developmental Disorders, 1-14. doi:10.1007/s10803-0142113-y

Sperry, L. A., \& Mesibov, G. B. (2005). Perceptions of social challenges of adults with autism spectrum disorder. Autism, 9(4), 362-376. doi: 10.1177/1362361305056077.

Strickland, D. C., Coles, C. D., \& Southern, L. B. (2013). JobTIPS: A transition to employment program for individuals with autism spectrum disorders. Journal of Autism and Developmental Disorders, 43(10), 2472-2483.

Szatmari, P., Bartolucci, G., Bremner, R., Bond, S., \& Rich, S. (1989). A follow-up study of high-functioning autistic children. Journal of Autism and Developmental Disorders, 19(2), 213-225.

Taylor, J. L., \& Mailick, M. R. (2013). A longitudinal examination of 10year change in vocational and educational activities for adults with autism spectrum disorders. Developmental Psychology, 50(3), 699708

Taylor, J. L., McPheeters, M. L., Sathe, N. A., Dove, D., VeenstraVanderWeele, J., \& Warren, Z. (2012). A systematic review of vocational interventions for young adults with autism spectrum disorders. Pediatrics, 130(3), 531-538.

Taylor, J. L., \& Seltzer, M. M. (2010). Changes in the autism behavioral phenotype during the transition to adulthood. Journal of Autism and Developmental Disorders, 40(12), 1431-1446. doi:10.1007/ s10803-010-1005-z.

Taylor, J. L., \& Seltzer, M. M. (2011). Employment and post-secondary educational activities for young adults with autism spectrum disorders during the transition to adulthood. Journal of Autism and Developmental Disorders, 41(5), 566-574. doi:10.1007/s10803010-1070-3.

Taylor, J. L., \& Seltzer, M. M. (2012). Developing a vocational index for adults with autism spectrum disorders. Journal of Autism and Developmental Disorders, 42(12), 2669-2679.

Test, D. W., Smith, L. E., \& Carter, E. W. (2014). Equipping youth with autism spectrum disorders for adulthood: promoting rigor, relevance, and relationships. Remedial and Special Education, 35(2), $80-90$.

Van Laarhoven, T., Winiarski, L., Blood, E., \& Chan, J. M. (2012). Maintaining vocational skills of individuals with autism and developmental disabilities through video modeling. Education and Training in Autism and Developmental Disabilities, 47(4), 447-461.

Venter, A., Lord, C., \& Schopler, E. (1992). A follow-up study of highfunctioning autistic children. Journal of Child Psychology and Psychiatry, and Allied Disciplines, 33(3), 489-507.

Vogeley, K., Kirchner, J. C., Gawronski, A., van Elst, L. T., \& Dziobek, I. (2013). Toward the development of a supported employment program for individuals with high-functioning autism in Germany. European Archives of Psychiatry and Clinical Neuroscience, 263(2), 197-203. doi:10.1007/s00406-013-0455-7.

Vornholt, K., Uitdewilligen, S., \& Nijhuis, F. J. N. (2013). Factors affecting the acceptance of people with disabilities at work: a literature review. Journal of Occupational Rehabilitation, 23(4), 463475. doi:10.1007/s10926-013-9426-0.

Wagner, M., Newman, L., Cameto, R., \& Levine, P. (2005). Changes over time in the early postschool outcomes of youth with disabilities: a report of findings from the National Longitudinal Transition Study (NLTS) and the National Longitudinal Transition Study-2 (NLTS2). Retrieved from http://files.eric.ed.gov/fulltext/ED494920.pdf

Wehman, P., \& Kregel, J. (1988). Supported competitive employment for individuals with autism and severe retardation: two case studies. Focus on Autism and Other Developmental Disabilities, 3, 1-13.

Wehman, P., Revell, G., \& Kregel, J. (1997). Supported employment research: expanding competitive employment opportunities for persons with significant disabilities. Retrieved from http://files.eric.ed. gov/fulltext/ED408777.pdf\#page $=10$

Wehman, P., Schall, C., Carr, S., Targett, P., West, M., \& Cifu, G. (2014). Transition from school to adulthood for youth with autism spectrum disorder: what we know and what we need to know. Journal of Disability, Policy Studies, 25(1), 30-40.

Wehman, P., Schall, C., McDonough, J., Kregel, J., Brooke, V., Molinelli, A., \& Thiss, W. (2013). Competitive employment for youth with autism spectrum disorders: early results from a randomized clinical trial. Journal of Autism and Developmental Disorders, 44(3), 487500. doi:10.1007/s10803-013-1892-x.

Wehman, P., Schall, C., McDonough, J., Molinelli, A., Riehle, E., Ham, W., \& Thiss, W. R. (2012). Project SEARCH for youth with autism spectrum disorders: increasing competitive employment on transition from high school. Journal of Positive Behavior Interventions, 15(3), 144-155. doi:10.1177/1098300712459760.

Westbrook, J. D., Fong, C. J., Nye, C., Williams, A., Wendt, O., \& Cortopassi, T. (2014). Transition services for youth with autism: a systematic review. Research on Social Work Practice, 1-11. doi:10. 1177/1049731514524836

Westbrook, J. D., Nye, C., Fong, C. J., Wan, J. T., Cortopassi, T., \& Martin, F. H. (2012). Adult employment assistance services for persons with autism spectrum disorders: effects on employment outcomes. Campbell Systematic Reviews. Retrieved from http:// ideas.repec.org $/ \mathrm{p} / \mathrm{mpr} / \mathrm{mprres} / 7398 . \mathrm{html}$

Whitehouse, A., Watt, H., Line, E., \& Bishop, D. (2009). Adult psychosocial outcomes of children with specific language impairment, pragmatic language impairment and autism. International Journal of Language \& Communication Disorders, 44(4), 511-528. doi:10. 1080/13682820802708098.

Wilczynski, S. M., Trammell, B., \& Clarke, L. S. (2013). Improving employment outcomes among adolescents and adults on the autism spectrum. Psychology in the Schools, 50(9), 876-887. doi:10.1002/ pits. 21718

Wing, L. (1989). Autistic adults. In C. Gillberg (Ed.), Diagnosis and treatment of autism (pp. 419-432). Göteborg: Plenum Press.

Wittenburg, D., \& Maag, E. (2002). School to where? A literature review on economic outcomes of youth with disabilities. Journal of Vocational Rehabilitation, 17(4), 265-280.

Yeager, P., Kaye, H. S., Reed, M., \& Doe, T.M. (2006). Assistive technology and employment: Experiences of Californians with disabilities. Work, 27, 333-344. 